\title{
Scientific Basis of Dealing with the Cost Issues in Routine Oncology Practice in Low \& Middle Income Countries
}

\author{
Ahmed Nadeem Abbasi \\ Section of Radiation Oncology, Aga Khan University, Karachi, Pakistan.
}

\section{BACKGROUND}

Cancer burden is increasing day by day in our Low and Middle Income Countries (LMIC) A practicing clinician faces the issue of cost of treatment in almost all patients who approach him or her for clinical consultation. More than often, the clinician has no formal training in cancer service development. Establishment of modern oncological services is dependent on financial resources available to the professionals who sit across an extra-large sized rectangular table and try to get the best out of the money pot. Some skeptics call it beauty out of the junkyard. The allocation of funds is dependent on the feasibility studies done by the healthcare economists . These wise guys seem to know a lot about the health of a nation, but many health care professionals have some reservations about their understanding of the practical knowledge of day to day managerial and clinical problems, faced by the person sitting at the receiving end.

In order to perform healthcare economic feasibility study in-depth know how is needed. As one can appreciate the interpretation of conclusions of these studies is also a difficult task. People who make policies also live in the same planet and they also consider certain predefined priorities. Most often than not, they have a pot of money and they have to allocate funds to a variety of new projects and to the existing services. Provision and allocation of funds is a complex issue and as one can imagine it is influenced by a variety of factors.

\section{SPECIFIC PROBLEMS ENCOUNTERED DURING CANCER SERVICE DEVELOPMENT}

Cost is an important component in overall care and management of cancer patients [1]. In many models of cancer management it is assumed that the individual or group of individuals performing the evaluation is standing-in for the society. Furthermore everyone thinks that the sole aim is targeted towards achieving a final goal of curing or controlling cancer in a given population. Financial resource issues are sometimes overlooked at the preliminary stages. The decision maker is one of us who are sitting at the hot seat

*Address correspondence to this author at the Section of Radiation Oncology, Aga Khan University, Karachi, Pakistan. E-mail: nadeem.abbasi@aku.edu and he or she has all the right reasons to believe that a single agenda approach is the only right way forward. Gradual allocation of funds over a finite period of time follows after that. When we go through the cancer service development plans we can comprehend that a global holistic view of overall care is seldom defined. Financial issues are not the only component of overall failures of a cancer service. The issue gets more complex and muddy when various layers of management get involved. Attempts made to ration the service provisions can lead to a totally funding dependent healthcare system. We can further elaborate this fact by taking the example of treatment options available to palliative oncology patients where we cannot offer a clear cut and significant survival benefit to the cancer patient. But we still treat them with the objective of improving their quality of life

Selection of appropriate model for the application of measurement tools and analysis of predefined outcome is fundamentally important.

\section{DEFINITION \& BRIEF DESCRIPTION OF COMMON TYPES OF HEALTHCARE PARAMETERS}

\section{Cost Effectiveness Analysis}

A predefined set endpoint is selected in this type of analysis. Cost effectiveness analysis compares this single primary outcome with cost estimated in monetary units. One of the selected outcomes is Quality adjusted life year (QALY). Various outcome measures are generally incorporated under heading [2].

\section{Q.A.L.Y (Quality Adjusted Life Year)}

This type of analysis adds up quality of life and the life's length into one single result. A zero to one index is calculated where zero score represents death and 'One" represents perfect normal health. Since last decade the usage of QALY as a parameter has enhanced [3].

\section{Cost Benefit Analysis}

In this form of analysis both cost and outcomes are valued in money and then the comparison is being made between the two. Cost-benefit analysis has its own de-merits. Many health professionals and public advocates do not agree with this 
marriage of convenience between the quality of life and valued length of life, especially when it is measured in pounds and pennies. Another potential fear in the minds of many people is that the cost benefit analysis can lead to rich getting more funding than the poor. This phenomenon can happen because of the fact that some members of the society would be happy to use their own financial resources in order to travel through that extra mile. The concept of income generation cannot be excluded from the decision making process.

\section{Cost Utility Analysis}

This form of analysis is basically a special type of cost effectiveness analysis, where observations were made on the basis of results measured in terms of gained QALYs.

Observations were made in various studies that people making decisions quote that it is not easy to understand the findings and the conceptual basis of the term of QALYs [4] and also it is not easy to define the steps involved in the processing of cost utility measurement and interpretation [5].

\section{The Process of Making Final Recommendations}

If the cancer service development planning is done halfheartedly we will end up adopting a system which will not yield the desired output. A potential danger exists at the planning stage. The anticipated danger will turn into a reality if in a given population cancer service development is mainly performed by health economists only without making any consultations with the patient advocacy groups and health professionals e.g. doctors and nurses.

I wish to quote some references pertaining to the final decision process. I quote Dr. Joanna Coast, who in the capacity of Senior Lecturer of Health Economics at the University of Bristol has recommended an alternative approach [2]. Dr. Joanna Coast had recommended to limit all evaluations pertaining to healthcare economics to the concept of cost-consequences. Healthcare policy makers can consider taking benefit of information displayed in a tabular format. Alternatively the multidisciplinary team members can also utilize financial measuring to obtain utility values. The relative efficiency of different options would depend on the implicit or explicit values attached by decision makers to the different elements of cost and outcome. Various options are compared in a easy to follow format which is displayed as tables [6].

\section{IMPORTANT PRACTICAL CONSIDERATIONS}

Application of economic evaluation in oncological service development has its own specific complexities. As discussed above, we can apply these theoretical models with some reservations keeping in view all the merits and de-merits attached with each process. We can learn from previous experiences. As healthcare providers, we are fully aware of the fact that when it comes to cancer management the term of quality of life is regarded as a multi-factorial phenomenon and it involves patients' social, emotional and physical well-being. Site specific multidisciplinary tumor boards provide an opportunity for the potential selection of best management plan for the patient. It is also expected that during the course of an open and healthy professional discussion a more cost effective management plan will emerge. Site specific tumor boards are a life line for cancer patients in LMIC [7, 8]. It would be worth mentioning that the incorporation of health economic processes in service development is quite a new area and we are still going through the learning curve.

In the United Kingdom, National Institute of Clinical Excellence (NICE) is also addressing the issues of cost and economic evaluations. NICE Clinical guidelines incorporate costing parameters as well. In future, it is expected that more networked bodies will be tackling the so-called fourth hurdle, that is, the issue which deals with the evidence of cost effectiveness [9-11].

Japan being the world's second largest health care economy in the world but currently it has no system of limiting market entry of drugs based on their cost effectiveness [12]. We cannot find published data on this particular subject, from other countries outside North America, Europe and Australia [1].

In low and middle income countries (LMIC) a positive change can occur with zero dollar extra investment, if we only make a fundamental decision of discussing all cases in site specific multi-disciplinary tumor boards. Another important quality measure is the introduction of peer reviewed practice in all disciplines of cancer care.

\section{CONFLICT OF INTEREST}

Declared None.

\section{ACKNOWLEDGEMENTS}

Declared None.

\section{REFERENCES}

[1] Abbasi AN. Development of cancer services: Potential specific complexiti in the perspective of health economic evaluation. J Coll Physicians Surg Pak 2013; 23(3): 171-2.

[2] Coast J. Is economic evaluation in touch with society's health values? BMJ 2004; 329: 1233-6.

DOI: $10.1136 / \mathrm{bmj} .329 .7476 .1233$

[3] Loomes G, McKenzie L. The use of QALYs in health care decision making. Soc Sci Med 1989; 28: 299-308.

DOI: 10.1016/0277-9536(89)90030-0

[4] Drummond M, Brown R, Fendrick AM, Fullerton P, Neumann 
$\mathrm{P}$, Taylor R. Use of pharmacoeconomics information-report of the ISPOR task force on use of pharmacoeconomic/health economic information in health-care decision making. Value Health 2003; 6: 407-16.

DOI: $10.1046 / j .1524-4733.2003 .64245 . x$

[5] Hoffman C, der Schulenburg JMG, EUROMET Group. The influence of economic evaluation studies on decision making. A European survey. Health Policy 2000; 52: 179-92.

DOI: $10.1016 / \mathrm{S} 0168-8510(00) 00076-2$

[6] Jacklin PB, Roberts JA, Wallace P, et al. Virtual outreach: Economic evaluation of joint teleconsultations for patients referred by their general practitioner for a specialist opinion. BMJ 2003; 327: 84. DOI: 10.1136/bmj.327.7406.84

[7] Abbasi AN. Cancer management is a multidisciplinary team work. J Coll Physicians Surg Pak 2011; 21(5): 259-61.

[8] Abbasi AN, Karim MU, Ali N, Hafiz A, Qureshi BM. Multi- disciplinary team tumour boards are a lifeline for our cancer patients in lower and middle income countries. Clin Oncol 2016; 28(12): 799. DOI: 10.1016/j.clon.2016.07.003

[9] Hutton J, Maynard A. A nice challenge for health economics. Health Econ 2000; 9: 89-9.

DOI: 10.1002/(SICI)1099-1050(200003)9:2<89::AID-HEC50 4>3.0.CO;2-G

[10] Benjamin I, Poston G, Sherlock D. Is the nice process flawed? Lancet 2002; 359: 2120.

DOI: 10.1016/S0140-6736(02)08933-X

[11] McKee M, Maclehose L, Mossialos E. After nice: Where now for health policy in the European Union? J R Soc Med 2003; 96: 1-2.DOI: 10.1177/014107680309600101

[12] Oliver A. Health economic evaluation in Japan: A case study of one aspect of health technology assessment. Health Policy 2003; 63: 197-204. DOI: 10.1016/S0168-8510(02)00066-0 